\title{
Long- Term Outcome of Hip Fracture in Elderly Rural Indian Population
}

\author{
Sunil Nikose ${ }^{1 *}$, Sohael Khan ${ }^{2}$, Pradeep Singh ${ }^{1}$, Mahendra Gudhe ${ }^{2}$, Mridul Arora ${ }^{2}$ and Sprash Naik ${ }^{3}$ \\ ${ }^{1}$ Professor, Department of Orthopedic surgery, Datta Meghe Institute of Medical Sciences, India \\ ${ }^{2}$ Assistant professor, Department of Orthopedic surgery, Datta Meghe Institute of Medical Sciences, India \\ 3 Junior Resident, Department of orthopaedic surgery, Datta Meghe Institute of Medical Sciences, India
}

Submission: December 07, 2016; Published: December 15, 2016

*Corresponding author: Sunil Nikose, Prof and Unit Head, Department of Orthopaedics, AVBRH, Sawangi (M), Wardha, Maharashtra, India (44200).

\section{Abstract}

Elderly population constitute majority of admissions in orthopedic facility due to hip fractures resulting commonly from trivial falls and less commonly from other mechanism of injuries. Hip fractures represent major lifestyle modifications and adjustments in elderly population

Purpose: The purpose of this study is to evaluate and determine the proportion of hip fracture in patients older than 65 years who experience long - term disability and morbidity due to hip fractures. A functional outcome following a hip fracture was carried out and results were compared with the pre injury activity level of the individuals.

Methods and materials: A prospective study was carried out at our institute from January 2011 to May 2014 in 1165 elderly patients who were admitted with hip fractures and patients were evaluated in terms of preinjury status and at regular interval till one year after the injury. Patients were treated by different means like non operative, reduction and osteosynthesis, hemiarthroplasty and total hip arthroplasty, depending on fracture type, presentation days after injury, consent and associated medical conditions. Data Included age, gender, injury mechanism, fracture stability, baseline preinjury functional status, timing of presentation to hospital, timing of surgery and medical complications.

Results: Outcome measures were used to evaluate recovery and patient evaluation based on rehabilitation following a hip fracture according to the available evidence on restrictions in activities of daily living. 737 (63.26\%) patients had fractures resulting due to trivial fall. $328(28.15 \%)$ patients of hip fracture did not acquire their pre-fracture levels 1 year post - injury. $8(0.68 \%)$ patients died within 3 months of fracture treatment. $32(2.74 \%)$ patients were treated by non-operative means due to various reasons. Of those patients who recovered well at pre-fracture levels of functioning, the maximum recovery time was less than 6 months. Increased hospital stay was due to comorbidity such as Type II Diabetes mellitus, associated cardiac conditions, development of pressure sores, and delirium in postoperative phase, which resulted in increased morbidity. Minor adverse events were postoperative delirium, electrolyte imbalance, urinary tract infection and pressure sores. Readmission rates after 3months were noted and found to be due to implant failure, deep seated infections and pressure sores.

Conclusion: The long-term consequences of hip fracture in elderly patients' injuries have profound effect on their lifestyle and have been associated with morbidity. Further studies are needed to assess potential of morbidity.

Keywords: Disability; Elderly population; femoral neck fractures; Hip fractures; Morbidity; Osteoporosis

Abbreviations: SSI: Surgical Site Infection; DVT: Deep Vein Thrombosis; ASA: American Society of Anesthesiologists; ORIF: Open Reduction and Internal Fixation; CI: Confidence Interval; HR: Hazard Ratio

\section{Introduction}

Hip fractures are amongst the most commonly seen fractures in emergency departments worldwide, especially in elderly populations over 65 years old [1] and most commonly results from low-energy trauma like simple falls. As medicine evolves, the life expectancy is increasing, leading to an increase in osteoporosis, a harbinger of hip fractures. It is expected that the number of hip fractures would rise to double worldwide by the year 2050 [2]. If the world numbers are to be believed, the estimated incidence of hip fracture will rise from 1.66 million in 1990 to about 6.26 million by the year 2050 [3]. 


\section{Orthopedics and Rheumatology Open Access Journal}

As three-quarters of the world's population reside in Asian subcontinent, it is projected that Asian countries will contribute more towards hip fractures in coming years, resulting in enormous health related economic burden and significantly altering health related quality of life, especially in elderly population. In India the figures would be much more, because it's presently the world's 2nd largest populated country with wide diversity between urban and rural population .Problems of the hip fractures in elderly population, especially in rural population are [1] Associated with substantial morbidity and mortality [2]. Malunion of fracture is common despite good fixation devices available presently [3] implant failure, causing the implant to cut-out of head and resulting in implant penetration into hip joint causing intractable continuous pain [4].

Added financial burden to already low socioeconomic income rural family [5] associated co morbid medical conditions like diabetes, hypertension, malnutrition and osteoporosis etc. which are overlooked due to poor socioeconomic condition. The reasons for mortality related to hip fractures may be numerous, but reduced mobility and rehabilitation after sustaining a hip fracture may be one of the most important contributory factors, both in increasing the incidence of morbidity and in prolonging the subsequent recovery. Specifically, a patient's physical activity and ability to walk, both preoperatively and postoperatively, seems to correlate with survival time.

Consequently, medical costs will also be increased significantly and exponentially, imposing an intense burden on already disorganized and strained health system. There will be many hurdles to overcome in years to come as resources become scarce and the health demand increases. Published mortality rates have varied from $12 \%$ to $50 \%$ at one year after hip surgery [4-10] and as high as 30\% at 2 years [11]. Surgical management of hip fracture in elderly are varied and the available common options include reduction and osteosynthesis, hemi arthroplasty, or total hip arthroplasty and depends on various factors like fracture geometry, physiological age of patient, available resources at hospitals and associated medical illnesses.

A hip fracture commonly includes all the fractures starting from the neck of the femur to the subtrochanteric region of proximal femur. For simplicity purposes, they are subdivided in three main categories depending on anatomical fracture location. Almost 90 - 95\%of hip fracture in elderly population comprises of neck and intertrochanteric fractures occurring in equal proportion, while the remaining 5 - $10 \%$ comprises of subtrochanteric fracture. Statistical data clearly indicate that one out of five women, aged 80 years or above, has sustained or will sustain a hip fracture [5].

Moreover, a fractured hip in elderly may lead to chronic disability, which might not recover and can also increase the incidence of fracture or age related complications leading to death. While rehabilitation interventions are meant to decrease the risks of falls for preventing hip fractures, post fracture rehabilitation care is important and crucial in recovery of the patient [12-17]. These rehabilitation interventions should be initiated as early as possible in post-operative phase and should be ideally continued till the individual has acquired maximum functional skills, physical activity and strength to be able to return within the community.

A detailed understanding of the newer treatment modalities, available resources at hospital and the appropriate medical management and rehabilitation strategies are necessary to minimize post fracture complications, morbidity and mortality. A combined approach of orthopedic surgeon along with physical therapist in early post-operative phase is usually the desired approach. The overall goal in the treatment of the geriatric hip fractures is to make an attempt to return the patient to the premorbid level of function [13-16].

The reasons for mortality after sustaining hip fractures may be numerous, but reduced mobility in elderly population may be one of the most important contributory factors, both in increasing the incidence of hip fractures themselves and in prolonging subsequent recovery [18]. Specifically, a patient's ambulatory status and physical activity both preoperatively and postoperatively, seems to correlate well with survival time [4].

The purpose of our study is to evaluate and determine the proportion of hip fractures in patients older than 65 years and those who experience long - term disability and morbidity due to hip fractures. A functional outcome evaluation following a hip fracture was carried out and results were compared with the pre injury activity level of the individuals.

\section{Aim and Objectives}

Aim of our study is to evaluate and determine the proportion of hip fractures in patients older than 65 years of age.

The objective was to evaluate the functional outcome following a hip fracture and to compare with the preinjury level activity of the individuals.

\section{Materials and Methods}

We included all the patients elder than 65 years with hip fractures as described attending trauma and orthopaedic department of our institute. A prospective study was carried out at our institute from January 2011 to May 2014. These patients were managed with non-operative means due to various reasons, fracture reduction and osteosynthesis, hemiarthroplasty and total hip arthroplasty, depending on fracture type, consent availability, socioeconomic status and willingness of patient and family, presentation days after injury and associated medical co morbid conditions. The data was analyzed was done with respect to age, gender, injury mechanism, fracture pattern related to stability of fracture, baseline preinjury functional status regarding ambulation and physical activity, 


\section{Orthopedics and Rheumatology Open Access Journal}

timing of presentation to hospital, timing of surgery and medical complications.

\section{Results}

A total of 1165 elderly patients, belonging to rural geographical region were included in the study with the mean age was $69.32 \pm 5.8$. Out of 1165 patients, the male patients were $468(40.17 \%)$ and female patients were 697 (59.82\%). A total of $663(56.90 \%)$ subjects of these elderly populations were independent ambulatory at pre -injury period324 (27.81\%) patients were ambulatory with some mild restrictions like the help of walking stick. 102 (8.75\%) elderly individuals were ambulatory with major restrictions in walking with a clear use of crutches or walker. $76(6.52 \%)$ of this population was non -ambulatory or were dependent on family members for ambulation or practically non- ambulatory (Table 1).

Table 1: Results.

\begin{tabular}{|c|c|c|c|}
\hline \multicolumn{1}{|c|}{} & Frequency & Percent \\
\hline \multirow{7}{*}{ Valid } & $\begin{array}{c}\text { Independent } \\
\text { Ambulatory }\end{array}$ & 663 & $56.90 \%$ \\
\cline { 2 - 4 } & $\begin{array}{c}\text { Ambulatory } \\
\text { with some } \\
\text { restriction }\end{array}$ & 324 & $27.81 \%$ \\
\cline { 2 - 4 } & $\begin{array}{c}\text { Ambulatory } \\
\text { with major } \\
\text { restriction }\end{array}$ & 102 & $8.75 \%$ \\
\cline { 2 - 4 } & $\begin{array}{c}\text { Non } \\
\text { ambulatory }\end{array}$ & 76 & $6.52 \%$ \\
\cline { 2 - 4 } & Total & 1165 & $100 \%$ \\
\hline
\end{tabular}

Complications related to fracture and modality of treatment was observed in operative and non -operative group of patients. Out of total 1165 patients, the recovery was uneventful in 897 (76.99\%) patients without any complications. 24 (2.06\%) patients had developed surgical site infection (SSI). In 79 (6.78\%) patients there were medical complications like electrolyte imbalance and CNS related manifestations like postoperative delirium etc. In 65 (5.57\%) patients there were recumbence related complications (development of sacral pressure sores). In 38 (3.26\%) patients implant failure was noted within three months of fracture fixation. In 45 (3.86\%) patients complications of Deep Vein thrombosis (DVT) of calf and thigh was noted in early postoperative phase within 21 days. A total of $17(1.46 \%)$ patients there was death during postoperative phase within one year of sustaining fracture. A total of $16(1.37 \%)$ patients died within three months of fracture treatment, and in one patient had death after three months and within one year of treatment.

According to the ASA (American Society of Anesthesiologists) Grading criteria, 226 (19.39\%) patients belonged to ASA Grade I, $571(49.01 \%)$ of the patients were in ASA Grade II, 128 (10.99\%) of the patients were in ASA Grade III and 240 (20.61\%) patients were in ASA Grade IV. 12 patients of ASA Grade IV (5\% of Grade IV and $1.03 \%$ of total patients) patients had mortality within three months' time. (P value $<0.05) .5$ patients $(3.90 \%$ of ASA Grade III and $0.43 \%$ of total patients) died within one years' time.

Intertrochanteric fractures were seen in 671 patients (57.59\%), intracapsular femoral neck fractures in 431 patients (36.99\%) and 63 (5.40\%) patients had sustained subtrochanteric fracture. We noted that the fracture configuration was not related to activity at the time of fall, or to the location of the fall. Treatment was individualized in each patient and modality of treatment depended on fracture location, days after presentation, socioeconomic status of patient and family. Nearly all intertrochanteric fractures were treated by open reduction and internal fixation (ORIF) with dynamic hip screw and plate fixation or proximal femoral nailing where as Intracapsular fracture were treated with hemiarthroplasty or total hip arthroplasty according to the state of joint and socioeconomic status of patient and family (Figure 1).

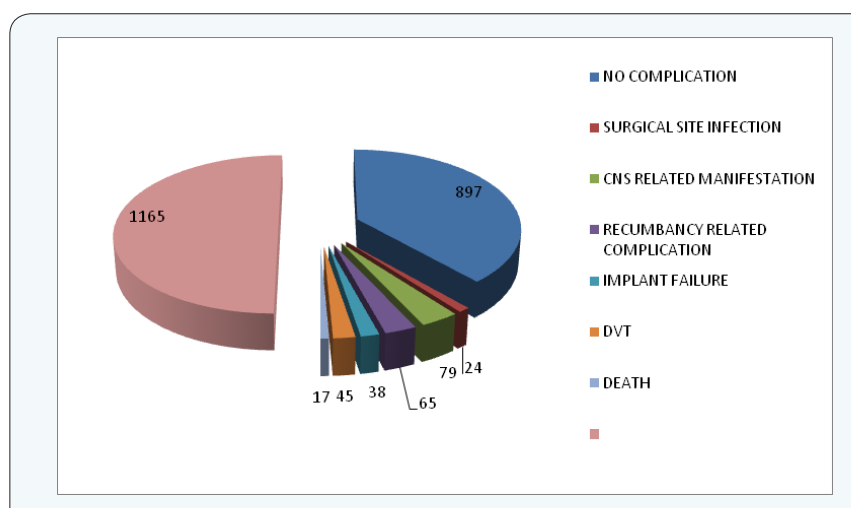

Figure 1: Complications.

Preoperatively, 92.5\% patients were ambulatory, either independently or with some form of restrictions, and $88 \%$ of the survivors at 1 year remained ambulatory. The risk of dying or being non- ambulatory 1 year postoperatively was increased in patients who were nonambulatory preoperatively and belonged mostly from ASA grade IV (hazard ratio [HR], 1.5; 95\% confidence interval [CI], 1.3-1.6; $\mathrm{P}<.0001)$, by increasing age of $>75$ years (HR, 1.8; 95\% CI, 1.2-2.6; $\mathrm{P}<.007$ ).

\section{Discussion}

Hip fractures are one of the leading causes of morbidity and mortality in the geriatric age group population. Many studies have been led to evaluate the factors playing a role in the falls and subsequent fractures in elderly patients [19-21]. Current study was designed to evaluate and determine the proportion of hip fracture in patients older than 65 years and to evaluate the long-term consequences after sustaining hip fracture in elderly patients.

The mean age incidence in various studies were as in Bolhofner et al. [22] 79 years, Sahlstrand [23] 75 years, Baumgaertner et al. [24] 77 years, Kanojia et al. [25] 56.79 


\section{Orthopedics and Rheumatology Open Access Journal}

years, Sedighi [26] 76.7 years. For our study age incidence was $69.32 \pm 5.8$ years as we have included only those patients who were more than 65 years of age.

Most common cause of mode of injury is stumbling and tripping which usually occurs indoors at a level ground [27-30]. In our study population, the most common cause of sustaining fracture was fall while working in the field as majority of our patient were laborer or farmer. Due to the deprived socio economic and deprived family support to the patients' presentation to the hospital is usually late. Average time of presentation to the hospital was 9 days and ranged from 0 to 23 days after injury. Delay in presentation in our study is explained by the lack of family emotional support for elderly patients, lack of transport infrastructure in rural area of India and socioeconomics in rural population in India. In intracapsular fractures of neck of femur, most of the elderly patients were managed with hemiarthroplasty or total hip replacement for early ambulation of these populations.

Whereas Wongwai and co-scientists [31], however, showed that delayed reduction and fixation of these fractures also brings good results, so the timing of surgery is a matter of debate. We preferred to perform hemiarthroplasty in patients of intracapsular fractures who were physiologically less active, presented late after injury and in older patients for need of early mobilization and early ambulation, and subsequently to avoid second surgery, in case the osteosynthesis related surgery, which has a high failure rate in geriatric age group. We performed reduction and internal fixation for patients who were physiologically active, Intertrochanteric and subtrochanteric fractures, presented early after injury along with some familial emotional support, so that in an event of failure of first surgery, subsequent surgery is not a problem. We observed that there was a direct correlation between presentation time after patients and familial emotional support and socioeconomic background. Major cause for this divergence may be a better optimization protocol for patients with co-morbidity and require added time for medical clearance prior to surgery.

The correlation between ASA grade and post-operative mortality has already been established and confirmed by other authors and in our data [32-34]. However we observed that the patient who were not ambulatory or minimally ambulatory before sustaining trauma showed higher percentage of morbidity and mortality. Study conducted at Scottish National Health Service [35] found 21\% mortality within 120 days. Similar work from New Zealand [36] used age-matched population data to attribute $15.6 \%$ of the cohort mortality at one year to the fractured hip process. In our study 16 patients died within 3 months of fracture treatment and remaining 1 patient died within one year after injury and its treatment. However the age group of study population at Scottish National Health service and New Zealand were approximately 12.2 year older than our study group population $[35,36]$.

\section{Conclusion}

Elderly patients with proximal femoral fracture usually recover and do well after surgery. The rate of recovery and the deterioration in patients' status is maximal within three months after injury / surgery. Rate of complications and mortality increases as the severity of grade of ASA grade increases. The rate of complications is directly proportional to presentation after injury and preinjury activity level. However, preinjury ambulatory status has direct impact on the ambulatory outcome after treatment of the proximal femoral fracture.

If the elderly patient survives without any major complications within first three months period after injury or surgery, then there is a good likelihood of recovery of the patient, and return to preinjury level is expected. However, Long term follow up is generally required to look for implant related problems, late infections. Prevention of falls in elderly population is would result in major reduction in injury burden and morbidity as well as reduced impact on socioeconomic status on already burdened rural household.

\section{References}

1. Macaulay W, Pagnotto MR. Iorio R, Mont MA. Saleh KJ (2006) Displaced femoralneck fractures in the elderly: hemiarthroplasty versus total hip arthroplasty. J Am Acad Orthop Surg 14 (5): 287-293.

2. Zi-Sheng A, You-Shui G, Zhi-Zhen J, Ting Y, Chang-Qing Z (2012) Hemiarthroplastyvs. primary total hip arthroplasty for displaced fractures of the femoral neckin the elderly. J Arthroplasty 27 (4): 583590.

3. Eventov I, Moreno M, Geller E, Tardiman R, Salama R (1983) Hip fractures in patients with Parkinson's syndrome. J Trauma 23(2): 98101.

4. Crane JG, Kemek CB (1983) Mortality associated with hip fractures in a single geriatric hospital and residential health facility: A ten-year review. J Am Geriatr Soc 31(8): 472-475.

5. Snaedal J, Thomgren M, Cedar L, Thorngren KG (1984) Outcome of patients with a nailed hip fracture requiring rehabilitation in a hospital for chronic care. Scand J Rehabil Med 16(4): 171-176.

6. Beals RK (1972) Survival following hip fracture: Long follow-up of 607 patients. J Chronic Dis 25(4): 235-244.

7. Miller CW (1978) Survival and ambulation following hip fractures. J Bone Joint Surg Am 60(7): 930-934.

8. Cedar L, Thomgren KG, Walkten B (1980) Prognostic indicators and early home rehabilitation in elderly patients with hip fractures. Clin Orthop Relat Res 152: 173-184.

9. Kauffman TL, Albright L, Wagner C (1987) Outcomes after rehabilitation in hip fracture patients over 90. Arch Phys Med Rehabil 68(6): 369-371.

10. Miller CW (1975) Quality criteria for the treatment of hip fractures. Va Med Mon102(12): 1032-1036.

11. Meessen JM, Pisani S, Gambino ML, Bonarrigo D, van Schoor NM, et al. (2014) Assessment of mortality risk in elderly patients after proximal femoral fracture. Orthopedics 37 (2): e194-200.

12. Tinetti M, Speechley M (1989) Prevention of falls among the elderly. $N$ Engl J Med 320(16): 1055-1059.

13. Dargent-Molina P, Favier F, Grandjean H, Baudoin C, Schott AM, et 
al. (1996) Fall related factors and risk of hip fracture: the EPIDOS prospective study. Lancet 348(9021): 145-149.

14. Ruchinskas R, Macciocchi S, Howe G, et al. (2001) Clinical decisionmaking in the rof falls. Rehabil Psychol 46: 262-70.

15. Santora TA, Schinco MA, Trooskin SZ (1994) Management of tauma in the elderly patient. Surg Clin North Am 74(1): 163-185.

16. Guidelines for the prevention of falls in the older persons: American Geriatrics Society, British Geriatrics Society, and American Academy of Orthopaedics Surgeons Panel on fall prevention (2001) J Am Geriatr Soc 49(5): 664-72.

17. Vivek Trikha, Shishir Rastogi (2005) Epidemiology and Rehabilitation of Hip Fractures in the Geriatric Population. IJPMR 16 (1): 16-19.

18. Wallace WA (1983) The increasing incidence of fractures of the proximal femur: An orthopedic epidemic. Lancet 1(8339): 1413-1414.

19.Jette AM, Harris BA, Cleary PD, Campion EW (1987) Functional recovery after hip fracture. Arch Phys Med Rehabil 68(10): 735-740.

20.Jarnlo G, Thorngren K (1991) Standing balance in hip fracture patients. Acta Orthop Scand 62(5): 427-434.

21.Greenspan SL, Myers ER, Maitland LA, Resnick NM, Hayes WC (1994) Fall severity and bone mineral density as risk factors for hip fracture in ambulatory elderly. JAMA. 271(2): 128-133.

22. Bolhofner BR, Russo PR, Carmen B (1999) Results of intertrochanteric femur fractures treated with a 135-degree sliding screw with a twohole side plate. J Orthop Trauma 13(1): 5-8.

23. Sahlstrand T (1974) The Richards compression and sliding hip screw system in the treatment of intertrochanteric fractures. Acta Orthop Scand 45(2): 213-219.

24. Baumgaertner MR, Curtin SL, Lindskog DM, Keggi JM (1995) The value of the tip-apex distance in predicting failure of fixation of peritrochanteric fractures of the hip. J Bone Joint Surg Am 77(7): 10581064.

25. Kanojia RK, Kulshreshta K, Tripathi KD, Verma AV (2002) Medialisation in management of unstable intertrochanteric fractures. Indian J Orthop 36: 10 .
26. Sedighi A, Sales JG, Alavi S (2012) The prognostic value of tip-to-apex distance (TAD index) in intertrochanteric fractures fixed by dynamic hip screw. Orthop Rev (Pavia) 4(4): e32.

27.Jarnlo GB, Thorngren KG (1991) Standing balance in hip fracture patients. Acta Orthop Scand 62(5): 427-434.

28.Greenspan SL, Myers ER, Maitland PR, Resnick NM, Hayes WC (1994) Fall severity and bone mineral density as risk factors for hip fracture in ambulatory elderly. JAMA 271(2): 128-133.

29.Ray WA, Groffin MR, Downey W (1989) Benzodiazepines of long and short duration half life and the risk of hip fracture. JAMA 262(23): 3303-3307.

30.Porter RW, Miller CG, Grainger D, Palmer SB (1990) Prediction of hip fracture in elderly women: A prospective study. BMJ 301(6753): 638641.

31. Farrow SC, Fowkes FG, Lunn JN, Robertson IB, Samuel P (1982) Epidermology in anaesthesia II: Factors affecting mortality in hospital. Br J Anaesth 54(8): 811-817.

32. Menke H, John KD, Klein A, Lorenz W, Junginger Th (1992) Praoperative Risikoeinschatzung mit der ASA-Klassification. Eine prospective Untersuchung zuMorbiditat and Letalitat in verschiedenen ASAKlassen bei 2937 Patienten mit allgemeinchirurgischen Operationen. Chirurg 63: 1029-1034

33. Cohen MM, Duncan PG (1988) Physical status score and trends in anesthetic complications. J Clin Epidemiol 41(1): 83-90.

34. Terdtoon Wongwai, Wiwat Wajanavisit, Patarawan Woratanarat (2012) Non-union and avascular necrosis of delayed reduction and screw fixation in displaced femoral neck fracture in young adults. J Med Assoc Thai 95: S120-7.

35.NHS Scotland, Information and Statistics Division. Scottish Hip Fracture Audit Report 2002.

36.New Zealand Health Information Service (2002) Fracture of Neck of Femur Services in New Zealand Hospitals 1999/2000.

Your next submission with JuniperPublishers will reach you the below assets

- Quality Editorial service

- Swift Peer Review

- Reprints availability

- E-prints Service

- Manuscript Podcast for convenient understanding

- Global attainment for your research

- Manuscript accessibility in different formats

( Pdf, E-pub, Full Text, A udio)

- Unceasing customer service

Track the below URL for one-step submission

http://juniperpublishers.com/online-submission.php 